Jerzy Jakubczyc

ORCID: 0000-0003-1903-6655

Uniwersytet Wrocławski

https://doi.org/10.19195/1733-5779.32.11

\title{
Wizualizacja skutków finansowych jako metoda oceny projektu
}

\section{JEL Classification: M2}

Słowa kluczowe: ocena projektu, metoda VoFI

Keywords: project appraisal, the VoFI method

Abstrakt: Omówiono metodę wizualizacji skutków finansowych, znaną jako metoda VoFI. Zwrócono uwagę na celowość poprawnego kojarzenia pojęcia wizualizacji z grafiką. W metodzie VoFI odwołano się do rozwiązania kontrowersyjnego. Pomimo zastrzeżeń pokazano, że metoda jest interesująca i powinna być szerzej stosowana w praktyce.

\section{Visualisation of financial implications as a project appraisal method}

\begin{abstract}
The VoFI or Visualisation of Financial Implications method has been discussed. It has been tried to explain if there is any reasonable connection between visualisation and graphics. Though the conclusion is not optimistic, it has been shown that the VoFI method is an interesting device and should be applied in the practice of project appraisals.
\end{abstract}

\section{Wprowadzenie}

Wartość obecna netto to nazwa popularnej metody oceny finansowej projektu. W literaturze można napotkać kontrowersyjne określenia wartości bieżącej netto lub zaktualizowanej wartości netto․ W pierwszym wypadku dość niefrasobliwie podchodzi się do różnicy między pojęciami „obecny” oraz „bieżący”. Wypada więc zwrócić uwagę na istnienie obecnej daty kalendarzowej albo obecnej chwili. Chwili nie można jednak mylić z okresem, czyli upływem czasu. Niestety, spotykany manieryzm jest tak powszechny, że walka z nim jest skazana na porażkę. Już

${ }^{1}$ Por. J. Jakubczyc, Metody oceny projektu gospodarczego. Podręcznik akademicki, Warszawa 2008, s. 205. 
tylko jako iskierka tli się nadzieja, że pojęcia chwili oraz okresu będą należycie rozróżniane. Dzięki temu powróci do łaski odmienność między takimi pojęciami, jak stan bogactwa oraz przepływ bogactwa. Wypada przy tym podkreślić, że między dwoma parami pojęć istnieją współzależności o różnorakim charakterze obrachunkowym, interpretacyjnym, a także biznesowym² ${ }^{2}$.

W literaturze używane jest też określenie metody NPV, czyli metody Net Pre-

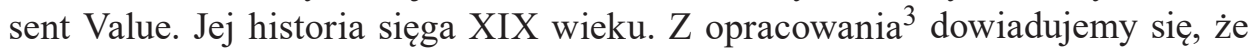
Karol Marks odniósł się do NPV jako do wielkości kapitału fikcyjnego. Co ciekawe, zaakceptował operację kapitalizacji, dyskontowanie zaś zostało zignorowane.

Minęły dwie dekady, by dowiedzieć się, że „tylko dyskontowanie ma sens, a kapitalizację można ignorować”. Autorem nakazu jest Irving Fisher, a cytat zaczerpnięto z pracy „The Theory of Interest” (New York 1930, pkt I.I. 32). Od początku lat trzydziestych XX wieku akceptowaną własnością metody NPV staje się dyskontowanie wielkości pieniężnych. W podręcznikach dominują rozmaite konfiguracje obrachunkowe; ilustracje natomiast są ignorowane. Zanikają też diagramy, czyli proste wykresy, które jeszcze trzydzieści lat temu były prezentowane w podręcznikach z inżynierii ekonomicznej jako wykresy profilów przepływów pieniężnych ${ }^{4}$. Podkreślona w tytule opracowania wizualizacja być może zapowiada powrót do korzystania z wykresów. Dowiemy się o tym z dalszej części rozważań.

\section{Metoda VoFI — projekt A}

Metodzie VoFI, czyli wizualizacji skutków finansowych (Visualization of Financial Implications), poświęcono osobny rozdział w książce pod tytułem „Investment Appraisal". Zwróćmy uwagę na tytuł książki. Nie ma w nim takich pojęć, jak valuation czy też pricing. Appraisal odnosi się do oceny, która niekoniecznie musi być prezentowana pieniężnie ${ }^{5}$.

W metodzie VoFI rolę główną odgrywają wartości bieżące (current values), których nie należy mylić z wartościami początkowymi (present values) lub z wartościami przyszłymi (future values). Ocena ostateczna jest formułowana po dokonaniu operacji dyskontowania lub kapitalizacji. Wybór nie ma większego znaczenia, ponieważ chodzi przecież o ocenę projektu, która nie musi być utożsamiana $\mathrm{z}$ wyceną.

Omówienie metody postanowiono oprzeć na przykładzie rozpatrywanej inwestycji rozwojowej ${ }^{6}$. W firmie brane są pod uwagę dwa warianty, które nazwano projekt A oraz projekt B. Szczegóły obu wariantów zamieszczono w tabeli 1.

2 Por. S. Armitage, The Cost of Capital. Intermediate Theory, Cambridge 2005, s. 32-45.

3 Net present value, https://en.wikipedia.org $>$ Net_present_value.

${ }^{4}$ C.S. Park, G.P. Sharp-Bette, Advanced Engineering Economics, New York 1990.

5 J. Jakubczyc, op. cit., r. IV.

${ }^{6}$ Por. U. Götze, D. Northcott, P. Schuster, Investment Appraisal. Methods and Models, Berlin-Heidelberg 2015, s. 100-108. 
Tabela 1. Dwa projekty dotyczące inwestycji rozwojowej

\begin{tabular}{|l|c|c|}
\hline \multirow{2}{*}{\multicolumn{1}{|c|}{ Wyszczególnienie }} & Projekt A & Projekt B \\
\cline { 2 - 3 } & \multicolumn{2}{|c|}{ (w EUR) } \\
\hline nakład inwestycyjny & 100000 & 60000 \\
\hline horyzont projektu & 5 (lat) & 4 (lata) \\
\hline wartość likwidacyjna & 5000 & 0 \\
\hline przepływy pieniężne netto: & & \\
$\mathrm{t}=1$ & 28000 & 22000 \\
$\mathrm{t}=2$ & 30000 & 26000 \\
$\mathrm{t}=3$ & 35000 & 28000 \\
$\mathrm{t}=4$ & 32000 & 28000 \\
$\mathrm{t}=5$ & 35000 & - \\
\hline Roczny koszt kapitału & 0,07 & 0,07 \\
\hline
\end{tabular}

Źródło: opracowanie własne.

Firma dysponuje kwotą 20000 (EUR) w gotówce, którą traktujemy jako fundusz własny. Lokata funduszu powinna zapewnić stopę zwrotu w wysokości 7\% rocznie. Zdarza się, że stopa zwrotu jest interpretowana jako koszt alternatywny kapitału, aczkolwiek nie jest to wielkość pieniężna. Dostępne na rynku finansowym papiery krótkoterminowe zapewniają roczną stopę zwrotu równą $6 \%$. Wielkość ta nie jest jednak traktowana jako koszt kapitału.

Sfinansowanie projektów A lub B wymaga podjęcia pożyczki bankowej — jednorazowej lub ratalnej. W obu wypadkach można liczyć tylko na 25\% kwoty niezbędnej do realizacji jednego projektu. Bez względu na rodzaj pożyczki bankowej obie są dostępne przy rocznej stopie odsetkowej równej 9\%. Zauważmy jednocześnie, jak odmiennie są traktowane liczby procentowe. Wielkość $25 \%$ ma powiązanie z kwotami 100000 (EUR) lub 60000 (EUR). Z kolei wielkości 6, 7 oraz 9\% są jedynie współczynnikami, pozbawionymi powiązań z kwotami pieniężnymi.

Brakujące środki można pozyskać drogą zaciągnięcia kredytu kupieckiego, kosztującego 11\% rocznie. Przyjmujemy, że wszystkie płatności będą dokonywane na koniec każdego roku, a odsetki będą naliczane na początku każdego roku kalendarzowego. Który projekt jest lepszy?

Treść przykładu jest zbliżona do rozważań zamieszczonych w pracy U. Götzego, D. Northcotta, P. Schustera pod tytułem „Investment Appraisal. Methods and Models" (Berlin-Heidelberg 2015). Uwzględniono też podobne określenia: stopy zwrotu; kosztu alternatywnego; kapitału oraz stopy odsetkowej. Wypada podkreślić, że stopy są jedynie współczynnikami liczbowymi i jako takie niewiele mają wspólnego z kosztem pieniężnym. Wspomniano jednak o stopie odsetkowej (interest rate), która w polskiej literaturze występuje jako stopa procentowa. W tym wypadku natrafiamy na osobliwość, gdyż w zagadnieniach oceny projektów określenie nie jest wykorzystywane. 
Tabela 2. Plan finansowy oraz bilanse płatnicze dla projektu A

\begin{tabular}{|c|c|c|c|c|c|c|}
\hline $\begin{array}{l}\text { Wyszczególnienie } \\
\text { (w EUR) }\end{array}$ & $\mathrm{t}=0$ & $t=1$ & $t=2$ & $t=3$ & $t=4$ & $t=5$ \\
\hline Cash flows z projektu & $-100000,00$ & $+28000,00$ & $+30000,00$ & $+35000,00$ & $+32000,00$ & $+35000,00$ \\
\hline Fundusz własny & \multicolumn{6}{|c|}{$+20000,00$} \\
\hline \multicolumn{7}{|l|}{ Kredyt ratalny } \\
\hline $\begin{array}{l}\text { Pożyczka } \\
(0,25 \times 100000)\end{array}$ & \multicolumn{6}{|c|}{$+25000,00$} \\
\hline $\begin{array}{l}\text { Zwrot ratalnie } \\
(25000 / 4)\end{array}$ & & $-6250,00$ & $-6250,00$ & $-6250,00$ & $-6250,00$ & 0 \\
\hline $\begin{array}{l}\text { Odsetki bankowe } \\
(0,09)\end{array}$ & & $-2250,00$ & $-1687,50$ & $-1125,00$ & $-562,50$ & 0 \\
\hline \multicolumn{7}{|l|}{ Kredyt zwykty } \\
\hline $\begin{array}{l}\text { Pożyczka } \\
(0,25 \times 100000)\end{array}$ & \multicolumn{6}{|c|}{$+25000,00$} \\
\hline Zwrot (redemption) & & & & & $-25000,00$ & 0 \\
\hline $\begin{array}{l}\text { Odsetki kredytowe } \\
(0,09)\end{array}$ & & $-2250,00$ & $-2250,00$ & $-2250,00$ & $-2250,00$ & 0 \\
\hline \multicolumn{7}{|l|}{ Kredyt kupiecki } \\
\hline Pożyczka & \multicolumn{6}{|c|}{$+30000,00$} \\
\hline Zwrot (redemption) & & $-13950,00$ & $-16050,00$ & 0 & 0 & 0 \\
\hline Odsetki kupieckie & & $-3300,00$ & $-1765,50$ & 0 & 0 & 0 \\
\hline \multicolumn{7}{|l|}{ Inwestycja finansowa } \\
\hline Reinwestycja & & & $-1997,00$ & $-25494,82$ & 0 & $-36624,73$ \\
\hline Likwidacja inwestycji & & & & & $+412,99$ & 0 \\
\hline Należne odsetki & & & & $+119,82$ & $+1649,51$ & $+1624,73$ \\
\hline Bilans finansowy & 0 & 0 & 0 & 0 & 0 & 0 \\
\hline \multicolumn{7}{|l|}{ Bilanse } \\
\hline Kredyt ratalny & $+25000,00$ & $+18750,00$ & $+12500,00$ & $+6250,00$ & 0 & 0 \\
\hline Kredyt zwykły & $+25000,00$ & $+25000,00$ & $+25000,00$ & $+25000,00$ & 0 & 0 \\
\hline Kredyt kupiecki & $+30000,00$ & $+16050,00$ & 0 & 0 & 0 & 0 \\
\hline Inwestycja finansowa & & & $-1997,00$ & $-27491,82$ & $-27078,83$ & $-63703,56$ \\
\hline Bilans netto & $-80000,00$ & $-59800,00$ & $-35503,00$ & $-3758,18$ & $+27078,83$ & $+63703,56$ \\
\hline
\end{tabular}

Źródło: opracowanie własne.

Według autorów książki Investment Appraisal istotą metody VoFI jest tabela prezentująca plan finansowy oraz bilanse płatnicze ${ }^{7}$. W wypadku dwóch porów-

7 Por. ibidem.

Studenckie Prace Prawnicze, Administratywistyczne

i Ekonomiczne 32, 2020

(C) for this edition by CNS 
nywanych projektów rozwojowych należy utworzyć dwie tabele. Pierwsza z nich została zamieszczona w tabeli 2.

Dwa pierwsze wiersze nie wymagają komentarza. W trzech następnych wierszach uwzględniono wielkość pożyczki opiewającej na kwotę 25000 (EUR), którą należy zwrócić w czterech równych ratach, po 6250 (EUR) każda. Trzeba też uwzględnić należne odsetki bankowe, które obliczono następująco:

$$
\begin{aligned}
25000 \times 0,09 & =2250,00(\text { EUR }) \\
18750 & \times 0,09=1687,50(\text { EUR }) \\
12500 \times 0,09 & =1125,00(\text { EUR }) \\
6250 \times 0,09 & =562,50(\text { EUR })
\end{aligned}
$$

Trzy kolejne wiersze dotyczą rozliczenia pożyczki inwestycyjnej, określonej jako kredyt zwykły. W chwili $t=0$ kwota 25000 (EUR) jest dopływem gotówki, a jej rozliczenie nastąpi w chwili $t=4$, czyli nastąpi jednorazowy odpływ gotówki w wysokości 25000 (EUR). Trzeba też uwzględnić płatne corocznie wielkości odsetek kredytowych, po 2250 (EUR) każda, czyli mamy do czynienia z identycznymi corocznie odpływami gotówki.

Trzy następne wiersze dotyczą rozliczenia kredytu kupieckiego z roczną stopą odsetkową równą 11\%. Zgodnie z decyzją biorcy kredytu chodzi o kwotę 30000 (EUR), która będzie spłacana w dwóch ratach.

Rata pierwsza na kwotę 13950 (EUR) ma być spłacona do końca roku pierwszego, a jej wysokość wynika z wyzerowania bilansu finansowego w chwili $t=0$. Oznacza to, że:

$28000-(6250+2250+2250+30000 \times 0,11+13950)=0($ EUR $)$.

Kwota 28000 (EUR) odpowiada wielkości dopływu pieniężnego do końca roku pierwszego i dotyczy pierwszego wiersza z tabeli 2 . Z kwoty tej muszą być sfinansowane wydatki na kredyt zwykły. Kwota 30000 (EUR)×0,11 = 3200 (EUR) oznacza należne do zapłaty odsetki za kredyt kupiecki. Ostatnia kwota (13 950 (EUR)) jest wielkością kalkulowaną, która oznacza wysokość spłaty ratalnej kredytu kupieckiego.

Rata druga kredytu kupieckiego to 30000 - $13950=16050$ (EUR). Należną spłatę trzeba powiększyć o odsetki, czyli o kwotę $16050 \times 0,11=1$ 765,50 (EUR).

Cztery kolejne wiersze dotyczą rozliczenia rozpatrywanej inwestycji rozwojowej. Zauważmy, że dla $t=2$ otrzymujemy nadwyżkę pieniężną, gdyż:

$30000-(6250+1687,50+2250+16050+1765,50)=1997,00$ (EUR).

Postawą rozliczenia jest kredyt kupiecki w wysokości 30000 (EUR). Z kredytu muszą być spłacone:

— rata kredytu zwykłego, opiewająca na kwotę 6250,00 (EUR);

— należne odsetki po $t=1$ oraz po $t=2$, czyli są to kwoty 2250 (EUR) oraz 1687,50 (EUR); 
— rata kredytu kupieckiego, czyli 16 050,00 (EUR);

— należne odsetki dla kredytu kupieckiego, czyli 1765,50 (EUR).

Dla $t=3$ należne do zapłaty odsetki wynoszą:

$1997,00 \times 0,06=119,82($ EUR $)$.

Zwróćmy uwagę, że uwzględniono stopę zwrotu równą 6\%, która została przyjęta dla krótkoterminowych papierów finansowych. Kwotę 119,82 (EUR) należy dodać do 35000 (EUR), czyli do dopływu gotówki z projektu dla $t=3$. Należy też odjąć kwotę 9625 (EUR), która wynika z sumy kwot: 6250 (EUR), 1125 (EUR) oraz 2250 (EUR). W efekcie dla $t=3$ otrzymujemy wielkość nadwyżki pieniężnej 25 494,82 (EUR), gdyż:

$35000-9625+119,82=25494,82$ (EUR).

Ostatni okres roczny projektu dotyczy $t=4$, a dokładniej odnosi się do należnych do zapłaty odsetek. W tym wypadku mamy:

$(25494,82+1997,00) \times 0,06=1649,51($ EUR $)$.

Kwotę 32000 (EUR) porównujemy z obliczoną nadwyżką pieniężną w wysokości 1649,51 (EUR), a także z odpływami środków pieniężnych, wynikającymi z kredytu ratalnego oraz z kredytu zwykłego. Otrzymujemy:

$(32000+1649,51)-34062,50=-412,99$ (EUR).

Oznacza to, że dla $t=4$ mamy do czynienia z niedoborem gotówki na kwotę 412,99 (EUR).

Do rozliczenia pozostał ostatni rok dla $t=5$. W tym celu rozważmy okres dla $t=2$, który kończy się nadwyżką pieniężną, gdyż:

30 000,00 - 28 003,00 = 1997,00 (EUR).

Nadwyżką kończy się też rok następny dla $t=3$. W tym wypadku otrzymujemy:

25 494,82 + 1997,00 = 27 491,82 (EUR).

Dla $t=4$ można obliczyć wielkość kapitału własnego, uwzględnionego w projekcie $\mathrm{A}$, a mianowicie:

$(27491,82 \times 1,06)-(34062,50-32000,00)=27$ 078,83 (EUR).

W podobny sposób obliczamy wielkość kapitału własnego dla $t=5$, czyli:

$(27078,83 \times 1,06)+35000,00=63703,56($ EUR $)$.

Kwotę 6 3703,56 (EUR) można utożsamiać z wartością przyszłą (future value) projektu rozwojowego.

Czy projekt A można ocenić jako finansowo dopuszczalny? Zainwestowana przez firmę kwota to 20000 (EUR). Kwotę traktujemy jako wielkość funduszu własnego, który corocznie powinien rosnąć o 7\%. Fundusz wsparto kredytami bankowymi i wraz z odsetkami zostały one spłacone. Oznacza to, że po upływie pięciu lat fundusz własny powinien osiągnąć wartość:

$20000 \times(1,07)^{5}=28051,03($ EUR $)$.

Uwzględniony rachunek prezentuje zastosowanie kapitalizacji, która kończy się wartością przyszłą funduszu na kwotę 28 051,03 (EUR). 
Dysponujemy dwoma wartościami przyszłymi — wartością przyszłą projektu A, czyli kwotą 63 703,56 (EUR), oraz wartością przyszłą funduszu własnego, czyli kwotą 28 051,03 (EUR). Ponieważ:

63 703,56 (EUR) > 28 051,03 (EUR),

więc projekt A należy ocenić jako finansowo dopuszczalny.

Zwróćmy uwagę, że dopuszczalność projektu nie musi bazować na wartości obecnej, co jest sugerowane w metodzie NPV. Tym samym otrzymujemy podpowiedź, że metody NPV nie należy absolutyzować czy też traktować jako bezdyskusyjny standard postępowania.

\section{Projekt B oraz wybór projektu lepszego}

Zanim przedstawimy kolejne niedoskonałości metody NPV, rozważmy projekt B, który jest przedsięwzięciem konkurencyjnym. Finansową specyfikację projektu B zamieszczono w tabeli 3, a jej budowa jest zbliżona do ujęcia uwzględnionego w tabeli 2 .

Podobieństwo budowy obu tabel sprawia, że postanowiono pominąć omawianie poszczególnych wierszy aż do części dotyczącej rozliczenia inwestycji rozwojowej. Przyjrzyjmy się wobec tego części ostatniej, prezentującej bilanse płatnicze.

Wielkości szczególnie ważne uwzględniono w wierszu prezentującym bilanse netto. Stwierdzamy, że w wypadku projektu B wartość przyszła opiewa na kwotę 58 766,62 (EUR). Po okresie $t=4$ taką właśnie kwotę należy wytransferować z projektu, by powiększyła kwotę kapitału własnego firmy. Pojawia się problem oceny tej kwoty. Obrachunek powinien przebiegać podobnie jak przy projekcie A. Jeśli tak, to otrzymujemy wynik:

$20000 \times(1,07)^{4}=26$ 215,92 (EUR) < 58 766,62 (EUR).

Stwierdzamy, że projekt B również jest dopuszczalny finansowo. Oba projekty jednak wykluczają się wzajemnie, a to oznacza, że należy wskazać na projekt lepszy.

W celu rozstrzygnięcia dylematu rozważmy tabele 4 i 5, które przepisano z części końcowych tabeli 2 dla projektu A oraz tabeli 3 dla projektu B. Zwróćmy uwagę na odmienności.

Zauważmy, że projekt B kończy się przy $t=4$, a projekt A jest kontynuowany do $t=5$. Horyzonty projektów są zatem odmienne, co wyklucza możliwość wykorzystania metody NPV. Poznajemy tym samym jej poważną niedogodność.

Porównując tabele 4 i 5, dostrzegamy istotne różnice między wielkościami pieniężnymi. Projekt A można nazwać jako duży, a projekt B jako mały. To z kolei oznacza, że porównywanie wielkości NPV dla obu projektów jest co najmniej dyskusyjne. Ujawnia się tym samym kolejna niedoskonałość metody NPV.

Czy oba projekty A i B mogą być porównywane? Odpowiedź jest pozytywna, ale nie w ujęciu pieniężnym, lecz w ujęciu względnym. 
Tabela 3. Plan finansowy oraz bilanse płatnicze dla projektu B

\begin{tabular}{|c|c|c|c|c|c|c|}
\hline $\begin{array}{l}\text { Wyszczególnienie } \\
\text { (w EUR) }\end{array}$ & $\mathrm{t}=0$ & $t=1$ & $t=2$ & $t=3$ & $t=4$ & $t=5$ \\
\hline $\begin{array}{l}\text { Cash flows } \\
\text { z projektu }\end{array}$ & $-60000,00$ & $+22000,00$ & $+26000,00$ & $+28000,00$ & $+28000,00$ & * \\
\hline Fundusz własny & $+20000,00$ & & & & & \\
\hline \multicolumn{7}{|l|}{ Kredyt ratalny } \\
\hline $\begin{array}{l}\text { Pożyczka } \\
(0,25 \times 60000)\end{array}$ & $+15000,00$ & & & & & \\
\hline $\begin{array}{l}\text { Zwrot ratalnie } \\
(25000 / 4)\end{array}$ & & $-3750,00$ & $-3750,00$ & $-3750,00$ & $-3750,00$ & $*$ \\
\hline $\begin{array}{l}\text { Odsetki bankowe } \\
(0,09)\end{array}$ & & $-1350,00$ & $-1012,50$ & $-675,00$ & $-337,50$ & $*$ \\
\hline \multicolumn{7}{|l|}{ Kredyt zwykty } \\
\hline $\begin{array}{l}\text { Pożyczka } \\
(0,25 \times 100000)\end{array}$ & $+15000,00$ & & & & & \\
\hline Zwrot (redemption) & & & & $-15000,00$ & $*$ & \\
\hline $\begin{array}{l}\text { Odsetki kredytowe } \\
(0,09)\end{array}$ & & $-1350,00$ & $-1350,00$ & $-1350,00$ & $-1350,00$ & $*$ \\
\hline \multicolumn{7}{|l|}{ Kredyt kupiecki } \\
\hline Pożyczka & $+10000,00$ & & & & & \\
\hline Zwrot (redemption) & & $-10000,00$ & 0 & 0 & 0 & $*$ \\
\hline Odsetki kupieckie & & $-1100,00$ & 0 & 0 & 0 & $*$ \\
\hline \multicolumn{7}{|l|}{ Inwestycja finansowa } \\
\hline Reinwestycja & & $-4450,00$ & $-20154,50$ & $-23701,27$ & $-10460,85$ & $*$ \\
\hline $\begin{array}{l}\text { Likwidacja } \\
\text { inwestycji }\end{array}$ & & & $*$ & $*$ & $*$ & $*$ \\
\hline Należne odsetki & & & $+267,00$ & $+1476,27$ & $+2898,35$ & $*$ \\
\hline Bilans finansowy & 0 & 0 & 0 & 0 & 0 & * \\
\hline \multicolumn{7}{|l|}{ Bilanse } \\
\hline Kredyt ratalny & $+15000,00$ & $+11250,00$ & $+12500,00$ & $+6250,00$ & 0 & $*$ \\
\hline Kredyt zwykły & $+15000,00$ & $+15000,00$ & $+25000,00$ & $+25000,00$ & 0 & $*$ \\
\hline Kredyt kupiecki & $+10000,00$ & 0 & 0 & 0 & 0 & $*$ \\
\hline $\begin{array}{l}\text { Inwestycja } \\
\text { finansowa }\end{array}$ & & $-4450,00$ & $-24604,50$ & $-48305,77$ & $-58766,62$ & * \\
\hline Bilans netto & $-40000,00$ & $-21800,00$ & $-2104,50$ & $-29555,77$ & $+58766,62$ & $*$ \\
\hline
\end{tabular}

Źródło: opracowanie własne. 
Tabela 4. Bilanse płatnicze dla projektu A

\begin{tabular}{|l|c|c|c|c|c|c|}
\hline \multicolumn{1}{|c|}{$\begin{array}{c}\text { Wyszczególnienie } \\
\text { (w EUR) }\end{array}$} & $\mathrm{t}=0$ & $\mathrm{t}=1$ & $\mathrm{t}=2$ & $\mathrm{t}=3$ & $\mathrm{t}=4$ & $\mathrm{t}=5$ \\
\hline kredyt ratalny & $+25000,00$ & $+18750,00$ & $+12500,00$ & $+6250,00$ & 0 & 0 \\
\hline kredyt zwykły & $+25000,00$ & $+25000,00$ & $+25000,00$ & $+25000,00$ & 0 & 0 \\
\hline kredyt kupiecki & $+30000,00$ & $+16050,00$ & 0 & 0 & 0 & 0 \\
\hline $\begin{array}{l}\text { inwestycja } \\
\text { finansowa }\end{array}$ & $-1997,00$ & $-27491,82$ & $-27078,83$ & $-63703,56$ & & \\
\hline bilans netto & $-80000,00$ & $-59800,00$ & $-35503,00$ & $-3758,18$ & $+27078,83$ & $+63703,56$ \\
\hline
\end{tabular}

Źródło: opracowanie własne.

Tabela 5. Bilanse płatnicze dla projektu B

\begin{tabular}{|l|c|c|c|c|c|c|}
\hline \multicolumn{1}{|c|}{$\begin{array}{c}\text { Wyszczególnienie } \\
\text { (w EUR) }\end{array}$} & $\mathrm{t}=0$ & $\mathrm{t}=1$ & $\mathrm{t}=2$ & $\mathrm{t}=3$ & $\mathrm{t}=4$ & $\mathrm{t}=5$ \\
\hline kredyt ratalny & $+15000,00$ & $+11250,00$ & $+12500,00$ & $+6250,00$ & 0 & $*$ \\
\hline kredyt zwykły & $+15000,00$ & $+15000,00$ & $+25000,00$ & $+25000,00$ & 0 & $*$ \\
\hline kredyt kupiecki & $+10000,00$ & 0 & 0 & 0 & 0 & $*$ \\
\hline $\begin{array}{l}\text { inwestycja } \\
\text { finansowa }\end{array}$ & $-4450,00$ & $-24604,50$ & $-48305,77$ & $-58766,62$ & $*$ & \\
\hline bilans netto & $-40000,00$ & $-21800,00$ & $-2104,50$ & $-29555,77$ & $+58766,62$ & $*$ \\
\hline
\end{tabular}

Źródło: opracowanie własne.

W ujęciu względnym odwołujemy się do wielkości relatywnych, reprezentowanych przez wskaźniki nazywane też stopami zwrotu z projektów. Zauważmy jednocześnie, że pojawia się galimatias pojęciowy. Akceptując z niechęcią niemały bałagan, spróbujmy jednak wskazać na projekt lepszy.

Rozpatrujemy najpierw projekt A. Obliczamy stopę zwrotu z projektu:

$$
r_{A}=\sqrt[5]{\frac{63703,56}{20000,00}}-1=0,2607=26,07 \%
$$

W wypadku projektu B obliczamy najpierw wartość przyszłą (future value), równą kwocie 62880,28 (EUR), przy rocznym koszcie własnym w wysokości 0,07. Stopa zwrotu z projektu B jest zatem następująca:

$$
r_{B}=\sqrt[5]{\frac{62880,28}{20000,00}}-1=0,2575=25,75 \%
$$

Ponieważ $\mathrm{r}_{\mathrm{A}}=26,07 \%>25,75 \%=\mathrm{r}_{\mathrm{B}}$, to stwierdza się, że projekt $\mathrm{A}$ jest lepszy od projektu B. 
Zwróćmy jednak uwagę na subtelności werdyktu. W wypadku projektu B tak zwana struktura czasowa jest korzystniejsza. Po porównaniu tabel 4 i 5 stwierdzamy, że bilanse netto dla projektu B zawierają relatywnie mniejsze ubytki w kapitale. Wydaje się, że uwzględnienie innego kryterium oceny, na przykład metody okresu zwrotu z inwestycji, może być interesującym rozwiązaniem ${ }^{8}$.

Wniosek świadczący na korzyść projektu B może też być wsparty stosownymi ilustracjami profilów pieniężnych. Niestety, oprócz tabel w metodzie VoFI nie znajdujemy takich rozwiązań. Zagadką pozostaje więc to, że w nazwie metody VoFI podkreślono obecność wizualizacji.

\section{Podsumowanie}

Nie bardzo wiadomo, dlaczego metodę VoFI powiązano z wizualizacją. Uwzględnione tabele trudno jest przecież zakwalifikować do grupy narzędzi wspomaganych grafiką. Być może odwołano się do triku marketingowego, licząc na atrakcyjność pojęcia wizualizacji.

Czy wobec tego metoda VoFI nie wnosi niczego nowego do arsenału narzędzi oceny projektów? Ostatnie wiersze z tabel 4 i 5 zawierają wielkości bilansowe netto. Przyjmuje się, że struktura bilansu prezentuje nie tylko stany bogactwa, lecz także składowe stanów. Stany pieniężne są jednak nagminnie mylone z przepływami pieniężnymi. W metodzie VoFI przypomniano więc o możliwości skorzystania z pojęcia stanu (state) pieniężnego, zaś przepływy (flows) pieniężne są użyteczne przy obserwowaniu wzrostów lub spadków w bogactwie.

\section{Bibliografia}

\section{Literatura}

Armitage S., The Cost of Capital. Intermediate Theory, Cambridge 2005.

Fisher I., The Theory of Interest, New York 1930.

Götze U., Northcott D., Schuster P., Investment Appraisal. Methods and Models, Berlin-Heidelberg 2015.

Jakubczyc J., Metody oceny projektu gospodarczego. Podręcznik akademicki, Warszawa 2008. Park C.S., Sharp-Bette G.P., Advanced Engineering Economics, New York 1990.

Weingartner H.M., Some New Views on the Payback Period and Capital Budgeting, „Management

Science" sierpień 1969.

\section{Źródła internetowe}

Net present value, https://en.wikipedia.org $>$ Net_present_value.

8 Por. H.M. Weingartner, Some New Views on the Payback Period and Capital Budgeting, „Management Science” sierpień 1969. 